\title{
Chapter 2 \\ Global Trends in Epidemiology of Coronavirus Disease 2019 (COVID-19)
}

\author{
Nishant Srivastava, Preeti Baxi, R. K. Ratho, and Shailendra K. Saxena
}

\begin{abstract}
In December 2019, suddenly 54 cases of viral pneumonia emerged in Wuhan, China, caused by some unknown microorganism. The virus responsible for these pneumonia infections was identified as novel coronavirus of the family Coronaviridae. The novel coronavirus was renamed as COVID-19 by WHO. Infection from the virus has since increased exponentially and has spread all over the world in more than 196 countries. The WHO has declared a Public Health Emergency of International Concern due to the outbreak of COVID-19. The virus is highly infectious and can cause human-to-human transmission. Every $24 \mathrm{~h}$, cases of COVID-19 increase severalfolds. The WHO is monitoring the SARS-CoV-2 spread very closely via a global surveillance system. The current situation demands the enforcement of strict laws which would help in inhibiting the further spread of COVID-19. Social distancing, international travel restrictions to affected countries, and hygiene are three important ways to nullify SARS-CoV-2.Government and private organizations need to come forward and work together during this pandemic. Public awareness, social distancing, and sterilization must be maintained to neutralize the viral infection, especially in major hot spots.
\end{abstract}

Nishant Srivastava and Preeti Baxi contributed equally as first author.

\footnotetext{
N. Srivastava

Department of Biotechnology, Meerut Institute of Engineering and Technology, Meerut, India

P. Baxi

Phytosanitary Laboratory, Department of Plant Molecular Biology and Biotechnology, Indira Gandhi Agriculture University, Raipur, India

R. K. Ratho

Department of Virology, Post Graduate Institute of Medical Education and Research, Chandigarh, India

S. K. Saxena $(\bowtie)$

Centre for Advanced Research (CFAR)-Stem Cell/Cell Culture Unit, Faculty of Medicine, King George's Medical University (KGMU), Lucknow, India

e-mail: shailen@kgmcindia.edu
} 
Keywords Coronavirus · COVID-19 · Epidemiology $\cdot$ SARS-CoV-2 · Global trends
Abbreviations
CDC Central Drug Council
$\mathrm{CoV}$ Coronavirus
COVID Coronavirus disease
HIV Human immunodeficiency virus
MERS Middle East respiratory syndrome
NIH National Institutes of Health
SARS Severe Acute Respiratory Syndrome
USA United States of America
WHO World Health Organization

\subsection{Introduction}

Infectious diseases have emerged as major threats to human existence since centuries and can devastate entire populations. Epidemiological studies have shown that millions of lives vanished due to these pandemic outbreaks. Epidemiology is defined by WHO as follows: "Epidemiology is the study of the distribution and determinants of health-related states or events (including disease), and the application of this study to the control of diseases and other health problems. Various methods can be used to carry out epidemiological investigations: surveillance and descriptive studies can be used to study distribution; analytical studies are used to study determinants."

In the past 100 years, the human race has encountered several epidemic diseases mostly associated with viruses. The twentieth century started with the outbreak of the pandemic H1N1 influenza virus in 1918, infecting one-third of the world's population and accounting for 50 million lives worldwide. It is known as the most deadly pandemic in the history of mankind. The influenza virus struck again in 1957-1958 in the form of the H2N2 influenza A virus, triggering a pandemic that claimed 1.1 million lives worldwide. Pandemic outbreaks are not new and occur from time to time. The major problem is controlling and developing effective solutions for these outbreaks as well as monitoring the viruses and other microbes closely for their mutations and cross-genetic translation. Table 2.1 provides a summary of major pandemic outbreaks that have occurred in the history of mankind till date (as per available sources; WHO, CDC, seeker.com and mphonline.com) (Lamb 2013; Bai et al. 2020; Staff 2020).

The outbreak of SARS-CoV-2 was first reported at Wuhan, China, in late December 2019. Initially the infection emerged as viral pneumonia from unknown microbial agents ( $\mathrm{Lu}$ et al. 2020). The Chinese Center for Disease Control and Prevention identified the virus as novel coronavirus from the throat swab sample of an infected patient on January 7, 2020 (Chen et al. 2020). Further, the WHO declared the disease as Public Health Emergency of International Concern in January 2020 and officially named the disease caused by the novel CoV2 as coronavirus 
Table 2.1 Major pandemic outbreaks in the history of mankind (Source: WHO, CDC USA)

\begin{tabular}{l|l|l|l|l}
\hline $\begin{array}{l}\text { S. } \\
\text { No. }\end{array}$ & $\begin{array}{l}\text { Pandemic disease } \\
\text { outbreak }\end{array}$ & $\begin{array}{l}\text { Organism responsible (virus/ } \\
\text { bacteria/protozoan) }\end{array}$ & $\begin{array}{l}\text { First outbreak/ } \\
\text { start (year) }\end{array}$ & $\begin{array}{l}\text { Number of } \\
\text { deaths }\end{array}$ \\
\hline 1 & $\begin{array}{l}\text { Plague of Galen } \\
\text { (Antonine Plague) }\end{array}$ & Measles/Variola virus & 165 A.D. & $\sim 5$ million \\
\hline 2 & $\begin{array}{l}\text { Bubonic plague (Plague } \\
\text { of Justinian) }\end{array}$ & Yersinia pestis & $540-542$ A.D. & $\begin{array}{l}\sim 25-50 \\
\text { million }\end{array}$ \\
\hline 3 & $\begin{array}{l}\text { Bubonic plague/Black } \\
\text { Death }\end{array}$ & Yersinia pestis & 1346 & $\begin{array}{l}\sim 200 \\
\text { million }\end{array}$ \\
\hline 4 & $\begin{array}{l}\text { Great Plague of } \\
\text { Marseille }\end{array}$ & Yersinia pestis & 1720 & $\sim 1$ million \\
\hline 5 & Cholera & Vibrio cholerae & $1817-1824$ & $<1$ million \\
\hline 6 & Russian flu & Influenza A/H2N2/ H3N8 & 1889 & $<1$ million \\
\hline 7 & Spanish flu & Influenza A/H1N1 & 1918 & $\begin{array}{l}20-50 \\
\text { million }\end{array}$ \\
\hline 8 & Asian flu & Influenza A/H2N2 & 1958 & $<2$ million \\
\hline 9 & Hong Kong flu & Influenza A/H3N2 & 1968 & $<1$ million \\
\hline 10 & AIDS & HIV & 1976 & $\begin{array}{l}\sim 36 \\
\text { million }\end{array}$ \\
\hline 11 & SARS-CoV & Coronavirus & $2002-2003$ & $>1000$ \\
\hline & & & &
\end{tabular}

Impact of COVID 19 as on March 25, 2020

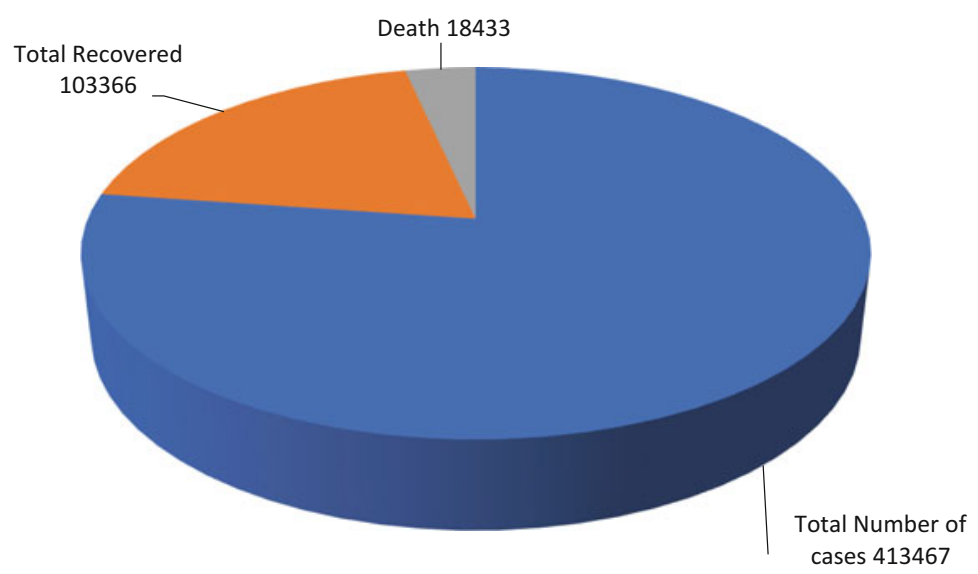

Fig. 2.1 (a) Worldwide reported cases, recovery, and death from COVID-19 as on March 25, 2020. (b) Worldwide increase in COVID-19 cases in 20 days (from March 25, 2020 to April 14, 2020)

disease 2019 (COVID-19) on February 12, 2020 (Adhikari et al. 2020; Zu et al. 2020). As per data available on various websites regarding COVID-19 infections worldwide, the cases are increasing exponentially. As on March 25, 2020, there were 413,467 reported cases, which included 18,433 deaths and 103,366 recovered cases which further rise $5 \times$ times to $18,48,439$ including 117,217 deaths and 485,303 recovered cases world-wide till April 14, 2020. Figure 2.1a and b depicts the 


\section{COVID CASES ENHANCEMENT IN 20 DAYS}

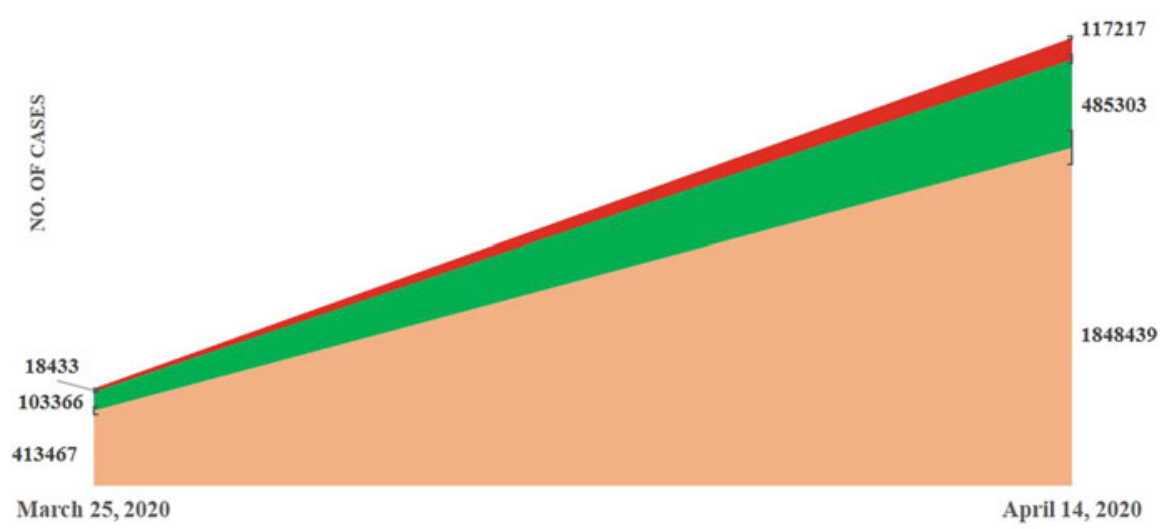

= Total Number of cases $\mid \mathbf{T}$ Total Recovered $\boldsymbol{\|}$ Death

Fig. 2.1 (continued)

distribution of virus infection with death and recovery data as per the webpage worldometers.info.

The first 54 reported cases of COVID-19 were observed in December 2019 at Wuhan, China, and this has now spread across the globe affecting 440,318 people in 195 countries. The severity of the infection increases due to its human-to-human transmission ability majorly by means of contact and large droplets. Additionally, it can also be transmitted through aerosols and fomite on various surfaces and cause infection (Perlman 2020). This chapter intends to provide an insight on the epidemiology of COVID-19 for a better understanding of disease patterns and distribution.

\subsection{Twenty-First Century Epidemics}

The twenty-first century started with the SARS-CoV outbreak in China in the year 2002-2003. The disease spread rapidly throughout the world and infected approximately 8098 people in 37 countries and caused 778 deaths. The outbreak of the disease created fear worldwide (worldatlas.com). The Dengue virus on other hand appears to be big threat of severe level which infects approximately 400 million people worldwide each year and approximately 100 million of infected patients require critical care facility whereas around 22,000 lost their life due to dengue infection. After the SARS outbreak, there were a series of epidemics such as dengue, encephalitis, MERS, Zika, Ebola, Avian Flu, etc., that were reported from various parts of the world. Table 2.2 depicts the various epidemics of the twenty-first century as well as their occurrence and affected population (Source: WHO, CDC, worldpress.com) (Nag 2018). 
Table 2.2 Epidemics of the twenty-first century

\begin{tabular}{l|l|l|l|l|l}
\hline S.No. & Disease & Organism & $\begin{array}{l}\text { Reported } \\
\text { year }\end{array}$ & $\begin{array}{l}\text { Number of people } \\
\text { affected }\end{array}$ & $\begin{array}{l}\text { Number of } \\
\text { deaths }\end{array}$ \\
\hline 1 & SARS-CoV & Coronavirus & $2002-2003$ & 8098 & 778 \\
\hline 2 & $\begin{array}{l}\text { Zimbabwean } \\
\text { cholera }\end{array}$ & Vibrio cholerae & 2008 & 8500 & 4369 \\
\hline 3 & Flu & $\begin{array}{l}\text { H1N1 Influ- } \\
\text { enza A }\end{array}$ & 2009 & & 18,000 \\
\hline 4 & $\begin{array}{l}\text { West African } \\
\text { meningitis }\end{array}$ & $\begin{array}{l}\text { Neisseria } \\
\text { meningitidis }\end{array}$ & 2009 & 13,516 & 931 \\
\hline 5 & Haitian cholera & Vibrio cholerae & 2010 & 80,000 & 9985 \\
\hline 6 & $\begin{array}{l}\text { Dengue fever } \\
\text { outbreak }\end{array}$ & Dengue viruses & 2011 & 21,204 & $<300$ \\
\hline 7 & MERS & Coronavirus & 2012 & 2494 & 858 \\
\hline 8 & Ebola & Ebola virus & 2013 & 28,600 & 11,325 \\
\hline 9 & Zika & Zika virus & $2013-2014$ & Approx. 2400 & $\begin{array}{l}29 \text { Babies in } \\
\text { Brazil (2015) }\end{array}$ \\
\hline 10 & Yemen cholera & Vibrio cholerae & 2016 & 269,608 & 1614 \\
\hline 11 & Nipah & Nipah virus & 2018 & 19 & 17 \\
\hline 12 & COVID-19 & SARS-COV2 & $2019-2020$ & 375,498 till & 16,362 till \\
March 25, 2020 & March 2020 \\
\hline
\end{tabular}

\subsection{SARS-CoV-2 Outbreak}

At the end of 2019, an unknown disease emerged and came into the spotlight. The disease caused pneumonia-like symptoms and lung fibrosis (Zhou et al. 2020). It emerged in the city of Wuhan, Hubei Province, China, which has a population of 11 million (Adhikari et al. 2020; Callaway et al. 2020; Chen et al. 2020; Fisher and Wilder-Smith 2020; Jingchun et al. 2020). China reported this pneumonia of unidentified cause first to the WHO country office on December 31, 2019 (WHO 2020). Since then, it has reported several thousand new cases of COVID-19. The peak of the epidemic in China was in late January and early February (Callaway et al. 2020). Up to January 31, 2020, COVID-19 had spread to 19 other countries, infecting 11,791 and causing 213 reported deaths. The COVID-19 epidemic was declared a Public Health Emergency of International Concern by the World Health Organization on January 30, 2020 (WHO 2020; Adhikari et al. 2020). It has since developed into a global pandemic and has affected huge numbers of people in Iran, South Korea, and Italy and has pushed a spike in worldwide cases across over 150 countries (Callaway et al. 2020).

On December 29, 2019, the WHO officially named the novel coronavirus as coronavirus disease 2019 (COVID-19). Currently, the virus is referred to as severe acute respiratory syndrome coronavirus 2 (SARS-CoV-2). According to reports, a number of people infected with pneumonia of unidentified cause were associated to a local seafood market in Wuhan, China, in December 2019. The Chinese Centre for Disease Control and Prevention (China CDC) immediately conducted 
epidemiological and etiological investigation. The WHO confirmed the association of the coronavirus outbreak with the seafood market of Wuhan (Sun et al. 2020). Immediately, scientists started to conduct research to find out the origin of the new coronavirus. The research group, led by Prof. Yong Zhang, were the first to publish the genome of COVID-19 on January 10, 2020 (Adhikari et al. 2020).

\subsection{Pandemic SARS-CoV-2/COVID-19}

Within a month of the outbreak at Wuhan, the SARS-CoV-2 virus extended rapidly all over China at the time of the Chinese New Year (Adhikari et al. 2020). The virus was not limited to a country. It was highly contagious and spread to more than 100 countries in the last 2-3 months and affected more than 300,000 people worldwide. As on March 24, 2020, the affected population is as follows: the Western Pacific Region under which China, Republic of Korea, Australia, Malaysia, Japan, Singapore, New Zealand, etc. come reported a total of 96,580 confirmed cases and 3502 deaths. On March 24, 2020, 943 new cases and 29 deaths were registered on a single day. The European Region (Italy, Spain, Germany, the United Kingdom, Norway, etc.) accounted for a total of 195,511 positive cases, out of which 24,087 were registered just in 1 day. The numbers peaked up to 10,189 confirmed cases and 1447 deaths in 1 day. In the Southeast Asia Region, 1990 confirmed cases were reported with 65 deaths. In the Eastern Mediterranean Region, a total of 27,215 people were affected and 1877 died due to this epidemic. In the Americas, 49,444 confirmed cases and 565 deaths were reported, with 12,428 new cases and 100 deaths registered in a day. Finally, in the African Region, 1305 confirmed cases and 26 deaths were reported. Table 2.3 provides a global scenario of the total number of COVID-19 positive cases and total number of deaths till March 25, 2020, taken from World health Organization situation report 2020.

As per WHO situation reports, the coronavirus started with a few positive cases but due to its highly contagious nature increased more than tenfold within 10 days' time.

In last 3 weeks, coronavirus disease has expanded rapidly across Europe, North America, Asia, and the Middle East, with the first confirmed cases identified in Latin American countries and African countries. Positive coronavirus cases outside China increased radically by March 16, 2020, and the number of affected countries, states, or territories reached 143 according to the WHO. Considering the alarming levels of infections and severity, the Director-General of WHO declared COVID-19 as a pandemic (Trevor Bedford et al. 2020). On March 13, 2020, the Director-General of the World Health Organization, Tedros Adhanom Ghebreyesus, said that Europe had become the epicenter of the pandemic (Trevor Bedford et al. 2020).

Figures 2.2 and 2.3 present the week-wise data of reported cases and deaths, respectively, in some of the majorly affected countries from January 21, 2020, to March 24, 2020,. Data has shown the exponential growth in the number of cases 
2 Global Trends in Epidemiology of Coronavirus Disease 2019 (COVID-19)

Table 2.3 Globally confirmed COVID-19 positive cases and deaths from January 21, 2020, to March 25, 2020 (based on coronavirus disease (COVID-2019) situation reports)

\begin{tabular}{|c|c|c|}
\hline WHO situation report & Globally confirmed cases & Globally reported deaths \\
\hline 21.01 .2020 & 282 & 6 \\
\hline 22.01 .2020 & 314 & 6 \\
\hline 23.01 .2020 & 581 & 17 \\
\hline 24.01 .2020 & 846 & 25 \\
\hline 25.01 .2020 & 1320 & 41 \\
\hline 26.01 .2020 & 2014 & 56 \\
\hline 27.01 .2020 & 2798 & 80 \\
\hline 28.01 .2020 & 4593 & 106 \\
\hline 29.01.2020 & 6065 & 132 \\
\hline 30.01 .2020 & 7818 & 170 \\
\hline 31.01 .2020 & 9826 & 213 \\
\hline 1.02 .2020 & 11,953 & 259 \\
\hline 2.02 .2020 & 14,557 & 305 \\
\hline 3.02 .2020 & 17,391 & 362 \\
\hline 4.02 .2020 & 20,630 & 426 \\
\hline 5.02 .2020 & 24,554 & 492 \\
\hline 6.02 .2020 & 28,276 & 565 \\
\hline 7.02 .2020 & 31,481 & 638 \\
\hline 8.02 .2020 & 34,886 & 724 \\
\hline 9.02 .2020 & 37,558 & 813 \\
\hline 10.02 .2020 & 40,554 & 910 \\
\hline 11.02 .2020 & 43,103 & 1018 \\
\hline 12.02 .2020 & 45,171 & 1115 \\
\hline 13.02 .2020 & 46,997 & 1369 \\
\hline 14.02 .2020 & 49,053 & 1383 \\
\hline 15.02.2020 & 50,580 & 1526 \\
\hline 16.02 .2020 & 51,857 & 1669 \\
\hline 17.02 .2020 & 71,429 & 1775 \\
\hline 18.02 .2020 & 73,332 & 1873 \\
\hline 19.02 .2020 & 75,204 & 2009 \\
\hline 20.02.2020 & 75,748 & 2129 \\
\hline 21.02 .2020 & 76,769 & 2247 \\
\hline 22.02 .2020 & 77,794 & 2359 \\
\hline 23.02 .2020 & 78,811 & 2462 \\
\hline 24.02 .2020 & 79,331 & 2618 \\
\hline 25.02.2020 & 80,239 & 2700 \\
\hline 26.02.2020 & 81,109 & 2762 \\
\hline 27.02.2020 & 82,294 & 2804 \\
\hline 28.02 .2020 & 83,652 & 2858 \\
\hline 29.02.2020 & 85,403 & 2924 \\
\hline 1.03 .2020 & 87,137 & 2977 \\
\hline 2.03 .2020 & 88,948 & 3043 \\
\hline 3.03 .2020 & 90,869 & 3112 \\
\hline
\end{tabular}


Table 2.3 (continued)

\begin{tabular}{l|l|l}
\hline WHO situation report & Globally confirmed cases & Globally reported deaths \\
\hline 4.03 .2020 & 93,091 & 3198 \\
\hline 5.03 .2020 & 95,324 & 3281 \\
\hline 6.03 .2020 & 98,192 & 3380 \\
\hline 7.03 .2020 & 101,927 & 3486 \\
\hline 8.03 .2020 & 105,586 & 3584 \\
\hline 9.03 .2020 & 109,577 & 3809 \\
\hline 10.03 .2020 & 113,702 & 4012 \\
\hline 11.03 .2020 & 118,319 & 4292 \\
\hline 13.03 .2020 & 125,260 & 4613 \\
\hline 14.03 .2020 & 132,758 & 4955 \\
\hline 15.03 .2020 & 142,534 & 5392 \\
\hline 16.03 .2020 & 153,517 & 5735 \\
\hline 17.03 .2020 & 167,515 & 6606 \\
\hline 18.03 .2021 & 179,111 & 7426 \\
\hline 19.03 .2020 & 191,127 & 7807 \\
\hline 20.03 .2020 & 209,839 & 8778 \\
\hline 22.03 .2020 & 234,073 & 9840 \\
\hline 23.03 .2020 & 266,073 & 11,183 \\
\hline 24.03 .2020 & 292,142 & 12,783 \\
\hline 25.03 .2020 & 332,930 & 14,509 \\
\hline & 372,757 & 16,231 \\
\hline 0.14 & 413,467 & 18,433 \\
\hline & & 5 \\
\hline
\end{tabular}

World Health Organization, 2020. https://www.who.int/emergencies/diseases/novel-coronavirus2019/situation-reports

$\llbracket$ China $\square$ Republic of Korea $\llbracket$ Italy $₫$ Spain $₫$ Germany $\backsim$ France $₫$ United States of America

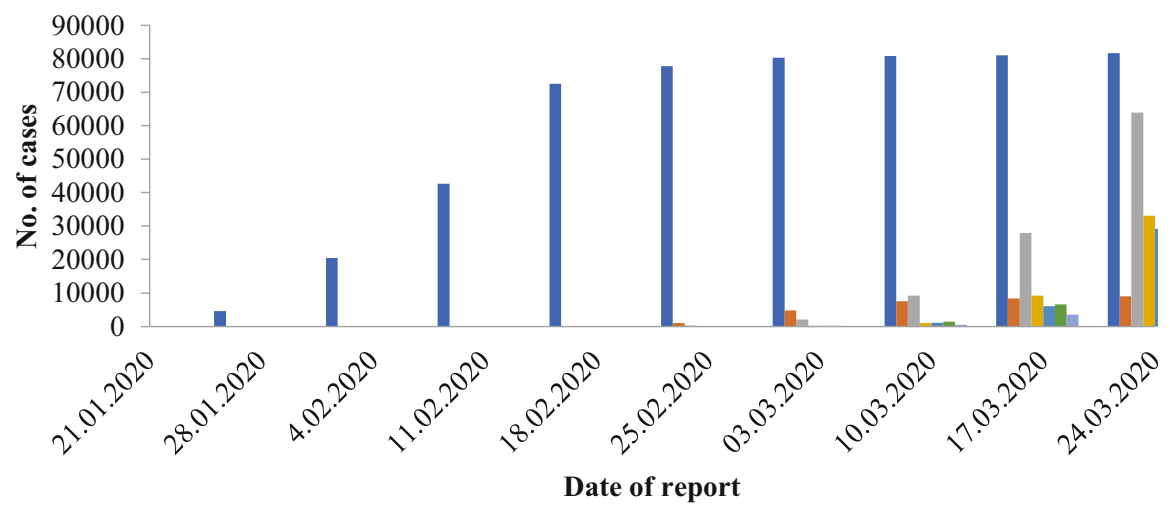

Fig. 2.2 Week-wise data of reported cases in some majorly affected countries (from January 21, 2020, to March 24, 2020). (Data taken from WHO situation reports) 


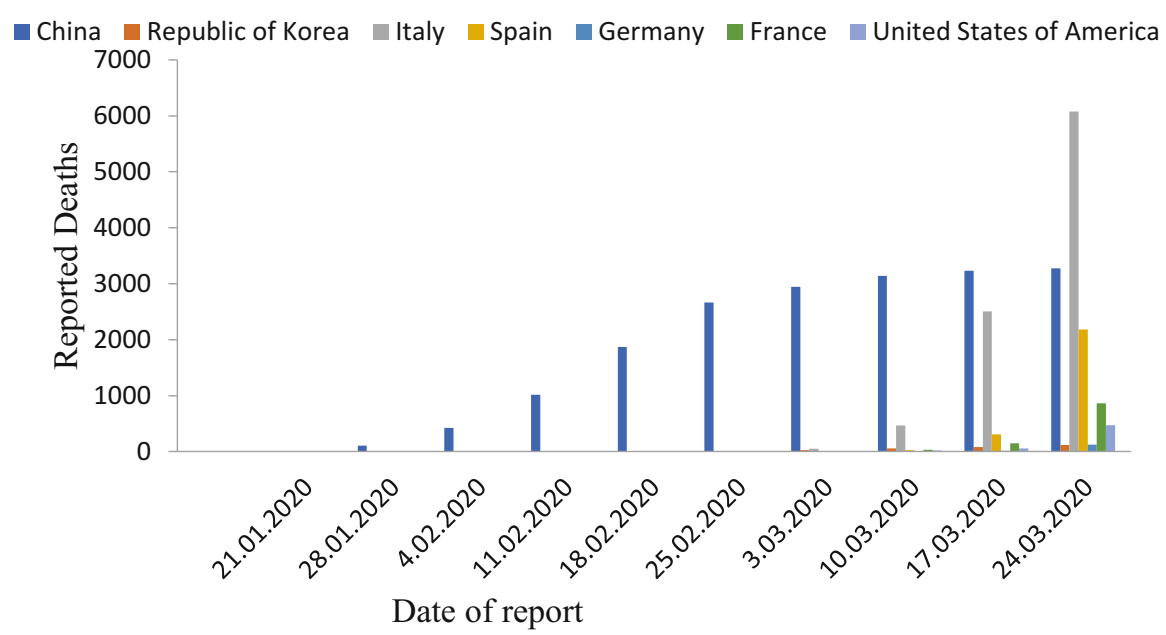

Fig. 2.3 Week-wise data of reported death cases in some majorly affected countries (from January 21, 2020, to March 24, 2020). (Data taken from WHO situation reports)

during the third week. China, Spain, Italy, and France all faced an explosion of cases in the third week.

\subsection{Worldwide Surveillance Systems}

As per the report published by WHO-China Joint Mission on Coronavirus Disease 2019 published on February 28, 2020, "The most of the global community is not ready for COVID 19." The disease emerged in China, and after several strict major decisions including lockdown to maintain social distancing, China successfully contained the virus. The number of new cases declined drastically (Fisher and Wilder-Smith 2020). The epicenter of the disease has now shifted to Europe, mainly to Italy and USA. The WHO is monitoring and tracking all the developments very closely around the world. The emergence of new cases as well as its spread to new countries and locations is being continuously tracked by the global monitoring system of the WHO. Apart from WHO surveillance, governments of various countries as well as their health ministries, home ministries, aviation, and non-government organizations are working together to keep a tab on the latest developments in COVID 19 cases. All the major airports of world were made fully equipped to scan and isolate passengers arriving from other countries or any other infected region.

Public health emergencies like COVID-19 require effective response in accurate time. Due to the insufficient information and suppress reporting on COVID19 outbreak from China many of the countries across the world were not able to 
understand the severity neither preprepared themselves to tackle this health emergency (Pisa 2020).

At national level, many governments developed a digital surveillance system to keep track of international travelers, isolated people, COVID-19 positive contacted people, and those with quarantine status. This close monitoring will help achieve a decline in COVID-19 cases as well as in containment of the virus. Additionally, several governments have developed online live digital tools to continuously monitor and update the current numbers of COVID-19 cases. The WHO live situation reports provide live status of emerging cases across the globe and pattern of disease spread. Besides this, some other independent agencies are also keeping close watch on COVID-19 development such as John Hopkins University, Centre for Disease Control, worldometer.info, NIH, etc. The Pandemicity project, a multilingual medical research database for $\mathrm{nCoV}-19$ started by pandemicity.org, includes several tools for screening and calculating risk factors of COVID-19 online. Many scientific publication houses are providing open access to COVID-19-related research works, which enables researchers worldwide to develop effective diagnostic and therapeutic solutions. The effective surveillance from local community level to regional level to national level to world level is the key to find effective solutions for containment of the virus. Worldwide surveillance also provides on-time alerts as to potential locations where the infection may be emerging. Additionally surveillance enables enhanced cooperation among affected countries for formulation of collective measures to fight pandemic like COVID19.

\subsection{Regions of Potential Threat}

The disease emerged from Wuhan, Hubei Province, China, as an unknown viral pneumonia diagnosed in 54 individual and by March 25, 2020, it had infected 81,848 people in China alone. Wuhan became the epicenter of COVID-19 just after emergence of the disease. Government and local bodies worked tirelessly to control the spread of COVID-19. Initially COVID-19 was not identified as a humanto-human transmission disease, but with exponential increase in cases research on COVID-19 established the fact that disease is transmitted from human to human via aerosol. The SARS-CoV-2 virus is a novel coronavirus of the family Coronaviridae and very little is known about its characteristics (Tekes and Thiel 2016; Ashour et al. 2020). As we gain more knowledge about CoV2, its spread is also increasing exponentially. The initial epicenter of the disease shifted from Wuhan to Europe to the USA. Italy appears worst affected having 69,176 reported cases till March 25,2020 , with the maximum number of deaths of 6820 infected people. USA with 51,914 positive cases is emerging as another epicenter. Since there is no vaccine or medication available for the novel coronavirus, social distancing and proper maintenance of self as well as surrounding sanitation is the only treatment. The long and strict lockdown in China shows excellent decline in viral infection and social distancing found very helpful in containment of the virus. The initial lighter attitude 
of European countries and the USA is one of the major reasons for their emergence as an epicenter of the disease. Highly populated countries like India must learn from the mistakes of these nations and implement strict measures for containment of the virus, as uncontrolled outbreak of the disease could lead to a devastating situation for developing countries like India. Another region of potential threat is Iran where the number of deaths has increased exponentially, with 2077 deaths recorded till March 25, 2020. Underdeveloped countries with lack of basic facilities, public awareness, and poverty like Pakistan and African countries may emerge as another epicenter for COVID-19. Special attention and extended help need to be given to such nations for fighting the pandemic.

\section{Executive Summary}

- 416,686 people were infected with SARS-CoV-2 till March 25, 2020 including 18,589 deaths.

- COVID-19 emerged from China and has now spread to 196 countries worldwide.

- The disease has been declared a Public Health Emergency of International Concern by WHO and as a global pandemic.

- On February 12, 2020, WHO renamed the novel CoV COVID-19.

- SARS-CoV-2 shows genetic similarity to SARS CoV and Bat CoV.

- Europe and USA have emerged as the new epicenters for COVID-19.

- World level surveillance with minute-by-minute tracking of COVID-19 is being performed by the WHO as well as some other government and private agencies.

- COVID-19 is a novel virus and proper precaution is the only cure.

- Maintenance of social distancing and proper hygiene is the only cure of COVID-19 till any vaccine is developed and made available.

\subsection{Conclusions}

SARS-CoV-2 is a highly infectious virus with the ability of human-to-human transmission. The virus is of zoonotic origin and was first transmitted into humans from animal (Menachery et al. 2018). SARS-CoV-2 has now spread to 196 countries, raising infection exponentially worldwide. Active worldwide surveillance is continuously being done by the WHO to monitor new cases, deaths, and recoveries. The mortality rate is quite low, ranging between 1.2 and $14 \%$, depending upon several parameters such as age, health condition, immunity, diabetes, and past disease records. International travel needs to be avoided to potential regions like Italy, USA, and China. Safety measures such as social distancing and maintenance of hygiene is top priority to secure self from COVID-19 infection. 


\subsection{Future Perspectives}

The epidemiology of COVID-19 provides a better understanding about the pattern of disease growth and spread. The high potential of COVID-19 causing infection from human to human may be neutralized by following social distancing and sanitization. Governments may impose lockdown and curfew for strict implementation of social distancing to reduce the spread of the infection. Worldwide surveillance system needs to be improved by use of artificial intelligence and information technology.

\section{References}

Adhikari SP, Meng S, Wu Y-J, Mao Y-P, Ye R-X, Wang Q-Z, Sun C, Sylvia S, Rozelle S, Raat H, Zhou H (2020) Epidemiology, causes, clinical manifestation and diagnosis, prevention and control of coronavirus disease (COVID-19) during the early outbreak period: a scoping review. Infect Dis Poverty 9(1):29

Ashour MH, Elkhatib FW, Rahman MM, Elshabrawy AH (2020) Insights into the recent 2019 novel coronavirus (SARS-CoV-2) in light of past human coronavirus outbreaks. Pathogens 9(3): E186

Bai Y, Yao L, Wei T, Tian F, Jin D-Y, Chen L, Wang M (2020) Presumed asymptomatic carrier transmission of COVID-19. JAMA 323(14):1406-1407

Callaway E, Cyranoski D, Mallapaty S, Stove E, Tollefson J (2020) The coronavirus pandemic in five powerful charts. Nature 579:482-483

Chen N, Zhou M, Dong X, Qu J, Gong F, Han Y, Qiu Y, Wang J, Liu Y, Wei Y, Xia JA, Yu T, Zhang X, Zhang L (2020) Epidemiological and clinical characteristics of 99 cases of 2019 novel coronavirus pneumonia in Wuhan, China: a descriptive study. Lancet 395(10223):507-513

Fisher D, Wilder-Smith A (2020) The global community needs to swiftly ramp up the response to contain COVID-19. Lancet 395(10230):1109-1110

Jingchun F, Xiaodong L, Weimin P, Mark WD, Shisan B (2020) Epidemiology of 2019 novel coronavirus disease-19 in Gansu Province, China, 2020. Emerg Infect Dis J 26(6). https://doi. org/10.3201/eid2606.200251

Lamb R (2013) 10 worst epidemics. https://www.seeker.com/10-worst-epidemics-1767852043. $\mathrm{html}$

Lu R, Zhao X, Li J, Niu P, Yang B, Wu H, Wang W, Song H, Huang B, Zhu N, Bi Y, Ma X, Zhan F, Wang L, Hu T, Zhou H, Hu Z, Zhou W, Zhao L, Chen J, Meng Y, Wang J, Lin Y, Yuan J, Xie Z, Ma J, Liu WJ, Wang D, Xu W, Holmes EC, Gao GF, Wu G, Chen W, Shi W, Tan W (2020) Genomic characterisation and epidemiology of 2019 novel coronavirus: implications for virus origins and receptor binding. Lancet 395(10224):565-574

Menachery VD, Gralinski LE, Mitchell HD, Dinnon KH, Leist SR, Yount BL, McAnarney ET, Graham RL, Waters KM, Baric RS (2018) Combination attenuation offers strategy for live attenuated coronavirus vaccines. J Virol 92(17):e00710-e00718

Nag OS (2018) The deadliest epidemics of the 21 st century so far. worldatlas.com/articles/thedeadliest-epidemics-of-the-21st-century-till-date.html

Perlman S (2020) Another decade, another coronavirus. N Engl J Med 382(8):760-762

Pisa M (2020) COVID-19, information problems, and digital surveillance. https://www.cgdev.org/ blog/covid-19-information-problems-and-digital-surveillance 
Staff (2020) Outbreak: 10 of the worst pandemics in history. https://www.mphonline.org/worstpandemics-in-history/

Sun K, Chen J, Viboud C (2020) Early epidemiological analysis of the coronavirus disease 2019 outbreak based on crowd sourced data: a population-level observational study. Lancet Digit Health 2(4):e201-e208

Tekes G, Thiel HJ (2016) Chapter six-feline coronaviruses: pathogenesis of feline infectious peritonitis. In: Ziebuhr J (ed) Advances in virus research, vol 96. Academic Press, New York, pp 193-218

Trevor Bedford RN, Hadfield J, Hodcroft E, Ilcisin M, Müller N (2020) Genomic analysis of nCoV spread. Situation report 2020-01-25. https://nextstrain.org/narratives/ncov/sit-rep/2020-01-25

WHO (2020) COVID19: rolling updates on coronavirus disease (COVID-19). https://www.who. int/emergencies/diseases/novel-Coronavirus-2019/events-as-they-happen

Zhou F, Yu T, Du R, Fan G, Liu Y, Liu Z, Xiang J, Wang Y, Song B, Gu X, Guan L, Wei Y, Li H, Wu X, Xu J, Tu S, Zhang Y, Chen H, Cao B (2020) Clinical course and risk factors for mortality of adult inpatients with COVID-19 in Wuhan, China: a retrospective cohort study. Lancet 395 (10229):1054-1062

Zu ZY, Jiang MD, Xu PP, Chen W, Ni QQ, Lu GM, Zhang LJ (2020) Coronavirus disease 2019 (COVID-19): a perspective from China. Radiology 200490 